\title{
Relationships between dimensionless models of ammonoid shell morphology
}

Horacio Parent, Matías Bejas, Andrés Greco, and Oyvind Hammer

Acta Palaeontologica Polonica 57 (2), 2012: 445-447 doi: http://dx.doi.org/10.4202/app.2010.0118

In morphological studies the shape may be conveniently quan tified by relative dimensions or dimensionless quantities. The analyses of shell morphology and morphospace occupation have been historically approachedmainly bymeans of statistical analysis on classical dimensions (distance measurements: diameter, umbilical width, whorl width, whorl height and apertural whorl height), the Raup's coiling and expansion rate parameters and, more recently, by means of the ADA-model which conjugates the classical variables in a single simple equation. Relationships between these studies should be possible based on mathematical equivalences between classical dimensions and those of coiling and expansion rates. These equivalences, which are presented in this paper, have been obtained on the basis of the ADA-model and a new general method for deriving dimensionless models of morphology based on exponential trajectories as a function of a rotational angle.

Key words: Ammonoid shell, morphology, size, shape, morphospace.

Horacio Parent [parent@fceia.unr.edu.ar], Laboratorio de Paleontología, IFG-FCEIA, Universidad Nacional de Rosario, Pellegrini 250, 2000 Rosario, Argentina; Matías Bejas [bejas@ifir-conicet.gov.ar] and Andrés Greco [agreco@fceia.unr.edu.ar ], Departamento de Física \& Instituto de Física de Rosario, CONICET, Universidad Nacional de Rosario, Pellegrini 250, 2000 Rosario, Argentina;

Oyvind Hammer [ohammer@nhm.uio.no], Natural History Museum, University of Oslo, Sars gt. 1, 0562 Oslo, Norway.

This is an open-access article distributed under the terms of the Creative Commons Attribution License (for details please see creativecommons.org), which permits unrestricted use, distribution, and reproduction in any medium, provided the original author and source are credited. 
Farf Full text (130.7 kB) ।

Foris Supplementary file (20.4 kB) 